\title{
Immortalized multipotent pericytes derived from the vasa vasorum in the injured vasculature. A cellular tool for studies of vascular remodeling and regeneration
}

\author{
Maki Kabara ${ }^{1}$, Jun-ichi Kawabe ${ }^{2}$, Motoki Matsuki ${ }^{1}$, Yoshiki Hira ${ }^{3}$, Akiho Minoshima ${ }^{1}$, Kohei Shimamura ${ }^{1}$, \\ Atsushi Yamauchi ${ }^{1}$, Tatsuya Aonuma ${ }^{1}$, Masato Nishimura ${ }^{1}$, Yukihiro Saito ${ }^{4}$, Naofumi Takehara ${ }^{2}$ and \\ Naoyuki Hasebe ${ }^{1,2}$
}

Adventitial microvessels, vasa vasorum in the vessel walls, have an active role in the vascular remodeling, although its mechanisms are still unclear. It has been reported that microvascular pericytes (PCs) possess mesenchymal plasticity. Therefore, microvessels would serve as a systemic reservoir of stem cells and contribute to the tissues remodeling. However, most aspects of the biology of multipotent PCs (mPCs), in particular of pathological microvessels are still obscure because of the lack of appropriate methods to detect and isolate these cells. In order to examine the characteristics of $\mathrm{mPCs}$, we established immortalized cells residing in adventitial capillary growing at the injured vascular walls. We recently developed in vivo angiogenesis to observe adventitial microvessels using collagen-coated tube (CCT), which also can be used as an adventitial microvessel-rich tissue. By using the CCT, CD146- or NG2-positive cells were isolated from the adventitial microvessels in the injured arteries of mice harboring a temperature-sensitive SV40 T-antigen gene. Several capillary-derived endothelial cells (CECs) and PCs (CPCs) cell lines were established. cECs and cPCs maintain a number of key endothelial and PC features. Co-incubation of CPCs with cECs formed capillary-like structure in Matrigel. Three out of six CPC lines, termed capillary MPCs demonstrated both mesenchymal stem cell- and neuronal stem cell-like phenotypes, differentiating effectively into adipocytes, osteoblasts, as well as schwann cells. mPCs differentiated to ECs and PCs, and formed capillary-like structure on their own. Transplanted DsRed-expressing mPCs were resident in the capillary and muscle fibers and promoted angiogenesis and myogenesis in damaged skeletal muscle. Adventitial mPCs possess transdifferentiation potential with unique phenotypes, including the reconstitution of capillary-like structures. Their phenotype would contribute to the pathological angiogenesis associated with vascular remodeling. These cell lines also provide a reproducible cellular tool for high-throughput studies on angiogenesis, vascular remodeling, and regeneration as well.

Laboratory Investigation (2014) 94, 1340-1354; doi:10.1038/labinvest.2014.121; published online 20 October 2014

Pericytes (PCs), also known as vascular mural cells, physically surround endothelial cells (ECs) in microvessels, including pre-capillary arterioles, capillaries, and post-capillary venules. ${ }^{1}$ PCs regulate the vascular tone, stability, maturation, and remodeling of vessels. ${ }^{1,2}$ In addition to their angiogenic features, some populations of PCs are defined as multipotent stem cells, including mesenchymal stem cells (MSCs), ${ }^{3,4}$ white adipocyte progenitors, ${ }^{5}$ skeletal muscle stem cells, ${ }^{6}$ and neural stem cells (NSCs). ${ }^{7}$ Because blood vessels are distributed throughout most tissues, multipotent PCs (mPCs) may be a major source of tissue-resident stem cells, which contribute to tissue renewal or remodeling after trauma, diseases, or aging. ${ }^{4}$ Commonly used PC markers, including the proteoglycan NG2, platelet-derived growth factor receptor beta (PDGFR $\beta$ ), and CD146, label heterogenous PC populations. ${ }^{1,2}$ To date, no specific marker is available to define the PC phenotype, including mPCs. ${ }^{8,9}$ Therefore, most aspects of the biology of mPCs are still obscure because of the lack of appropriate methods to detect and isolate these mutipotent PCs.

\footnotetext{
${ }^{1}$ Division of Cardiovascular, Respiratory and Neurology, Department of Medicine, Asahikawa Medical University, Asahikawa, Japan; ${ }^{2}$ Department of Cardiovascular Regeneration and Innovation, Asahikawa Medical University, Asahikawa, Japan; ${ }^{3}$ Department of Anatomy, Asahikawa Medical University, Asahikawa, Japan and ${ }^{4}$ Department of Vascular Surgery, Asahikawa Medical University, Asahikawa, Japan

Correspondence: Professor J-i Kawabe, MD, PhD, Department of Cardiovascular Regeneration and Innovation, Asahikawa Medical University, Midorigaoka, Higashi 2-1-1, Asahikawa, Hokkaido 0788510, Japan.

E-mail: kawabeju@asahikawa-med.ac.jp

Received 2 February 2014; revised 14 July 2014; accepted 27 July 2014
} 
The tunica adventitia of large blood vessels consisting of the collagen-rich extracellular matrix, stromal cells/fibroblasts, the vasa vasorum, and perivascular nerves, has been recognized just as a passive structural player. ${ }^{10}$ However, the importance of the tunica adventitia was recently reevaluated. Adventitial neovascularization is associated with atherosclerotic plaque progression. ${ }^{11-13}$ Development of an immature neointimal vasa vasorum results in the delivery of blood substrates, including inflammatory cells and lipids, into plaques and the plaque hemorrhages, thereby contributing to the enlargement of plaque growth and destabilization, which are believed to increase the risk of vessel occlusion. ${ }^{14}$ Recent studies have demonstrated the existence of adventitial stem/progenitor cells, including mPCs as a system reservoir for tissue-resident stem cells. ${ }^{15-17}$ In a vascular remodeling setting following vascular injury, in parallel with adventitial neovascularization, adventitial progenitor cells start a process of proliferation, migration and differentiation and contribute to vascular remodeling. ${ }^{18,19}$ Therefore, the growing vasa vasorum may serve as a vascular niche for adventitial stem cells, including mutipotent PCs, and plays an active role in vascular remodeling. ${ }^{17}$

A transgenic mouse harboring the temperature-sensitive SV40 large T-antigen gene (tsSV40Tg mouse) expresses inactive tsSV40 in all tissues. When the isolated cells are cultured at $33^{\circ} \mathrm{C}$, cells can be easily immortalized by the activation of tsSV40. ${ }^{20}$ When the immortalized cells are incubated at temperatures $>37^{\circ} \mathrm{C}$, the tsSV40 is degraded, and the cells exhibit specific phenotypes similar to the original cells. This strategy has been successfully utilized for establishing immortalized cell lines from tissues with small dimensions to clarify the characteristics of certain kind of cells that are somewhat difficult to prepare each time from native tissues. Although PCs are found in capillaries that are distributed throughout most tissues, it is difficult to isolate PCs within the whole tissue, because commonly used PC markers are not PC-specific and differ depending on the tissue and even the developmental stage. ${ }^{4}$ By using tsSV40Tg mice, immortalized PC lines have been established only from certain restricted capillary-rich tissues, such as the retina and capillaries isolated from brain tissue. ${ }^{21,22}$ However, PCs from capillaries in other peripheral tissues, especially in the pathological setting, have not been established.

Recently, we have developed a new in vivo angiogenesis assay using a collagen-coated tube (CCT) to observe adventitial microvasculature growing around injured arterial walls. ${ }^{23}$ The thin collagen membrane (CCT membrane), in which microvessels are present at a high density and are distributed twodimensionally, can be examined quantitatively for adventitial angiogenesis. ${ }^{23}$ We noticed that the CCT membrane can also be used as an ideal microvessel-rich tissue from which we can isolate adventitial capillary cells. In the present study, using the unique CCT method, we successfully established immortalized capillary cells from the growing adventitial microvessels of injured femoral walls of tsSV40Tg mice.

\section{MATERIALS AND METHODS \\ Animals}

Transgenic mice harboring the tsSV40 large T-antigen gene were donated by FACT (Sendai, Japan). All animal experiments were performed according to procedures approved by the Animal Care and Use Committee of Asahikawa Medical University.

\section{Preparation of CCT-Membranes and Cells}

A wire-mediated vascular injury model was generated as described previously. ${ }^{24}$ A CCT was attached just beside the injured femoral artery. ${ }^{23}$ Two weeks after the surgery, the collagen-layer on the CCT (CCT membrane) was removed. The microvessel-rich CCT membrane was cut into $2-\mathrm{mm}$ pieces and incubated in $500 \mu \mathrm{g} / \mathrm{ml}$ Liberase DL (Roche, Basel, Switzerland) in Hanks' buffered solution for $30 \mathrm{~min}$ at $37^{\circ} \mathrm{C}$. The isolated cells were incubated with Dulbecco's modified Eagle's medium (DMEM) supplemented with 10\% fetal bovine serum (FBS), $100 \mathrm{U} / \mathrm{ml}$ penicillin, and $100 \mu \mathrm{g} / \mathrm{ml}$ streptomycin at $33^{\circ} \mathrm{C}$ in a $\mathrm{CO}_{2}$ incubator.

\section{Isolation of Capillary Cells and Establishment of Cell Lines}

After the cells were subcultured for two passages, they were re-suspended in buffer A (phosphate-buffered saline (PBS) containing $0.5 \%$ bovine serum albumin (BSA) and $2 \mathrm{mM}$ EDTA). To isolate capillary-derived ECs (cECs) and PCs (cPCs), the cells were incubated with anti-CD146- or NG2MicroBeads. The MicroBeads-reacted cells $\left(9.55 \% \mathrm{CD} 146^{+}\right.$ cells and $6.28 \% \mathrm{NG}^{+}$cells) were isolated from the total cells using a magnetic cell sorting system (Miltenyi Biotec, Bergisch Gladbach, Germany). For cECs, CD146 ${ }^{+}$cells were incubated at $33^{\circ} \mathrm{C}$ on fibronectin-coated dishes with endothelial basal medium (EBM2; Lonza, Basel, Switzerland) containing $20 \mathrm{ng} / \mathrm{ml}$ vascular endothelial growth factor (VEGF), $10 \mathrm{U} / \mathrm{ml}$ heparin, and $10 \%$ FBS. For cPCs, NG2 ${ }^{+}$ cells were suspended in DMEM containing 10\% FBS, and incubated at $33^{\circ} \mathrm{C}$. For the establishment of cloned cell lines, single cells were seeded in collagen-coated 96-well plates at diluted densities, and the cells of each formed colony were collected. To trace injected cells within tissues, cells were infected with a retrovirus harboring the DsRed or green fluorescent protein (GFP) genes to label living cells. Fluorescence-expressing cells were sorted using fluorescenceactivated cell sorting (FACS) flow cytometry (FACSAria II, Beckman Coulter, Brea, CA).

\section{Reverse Transcription-Polymerase Chain Reaction Analysis}

Reverse transcription-polymerase chain reaction (RT-PCR) analysis was performed as described previously. ${ }^{25,26}$ Briefly, total RNA was extracted from cells using the RNeasy mini kit (Qiagen, Hilden, Germany). RT-PCR was carried out with the SuperScript One-Step RT-PCR kit (Invitrogen, Carlsbad, $\mathrm{CA})$ in the presence of $10 \mu \mathrm{mol} / \mathrm{l}$ sense and anti-sense 
primers. Sequences of the specific primers are shown in Supplementary Table 1.

\section{Gene Microarray Analysis}

For the oligo DNA microarray analysis, RNA samples were collected on day 6 after adipogenesis differentiation at $37^{\circ} \mathrm{C}$. RNA samples from cells without induction were used as the control. The 3D-Gene Mouse Oligo chip 24k (Toray Industries, Tokyo, Japan) was used. The Cy3- or Cy5-labeled aRNA was pooled and dissolved in hybridization buffer and was hybridized for $16 \mathrm{~h}$. Hybridization signals were scanned using the 3D-Gene Scanner (Toray Industries) and processed by 3D-Gene Extraction software (Toray Industries). Raw data intensities $>2$ s.d. of the background signal intensity were considered valid. The detected signals for each gene were normalized by the global normalization method ( $\mathrm{Cy} 3 / \mathrm{Cy} 5$ ratio median $=1$ ).

\section{Flow Cytometry Analysis}

For flow cytometry analysis, cells were suspended in buffer A, incubated with specific primary antibodies, and then stained with secondary antibodies. The negative control sample was incubated with a non-specific antibody of the same isotype as the specific primary antibody, and stained with the same secondary antibody. Cells were analyzed using a flow cytometer (Cytomics FC500TM, Beckman Coulter). The primary antibodies used in this study include those against CD11b, CD29, CD31, CD34, CD44, CD45, CD73, CD105, CD106, Sca1, Fabp4, and oligodendrocyte marker O4 (R\&D Systems, Minneapolis, MN), NG2, CD146 (Abcam, Cambridge, UK), alpha-smooth muscle actin ( $\alpha$ SMA; Sigma, St Louis, MO).

\section{Immunohistological Analysis}

The skeletal muscle tissue was embedded in optimal cutting temperature compound, and transverse cryosections $(10 \mu \mathrm{m})$ were dried on glass plates. Sections were fixed with $4 \%$ paraformaldehyde (PFA)/PBS for $30 \mathrm{~min}$. For immunostaining, the cells were fixed with $2 \%$ PFA/PBS for $20 \mathrm{~min}$. In particular, cECs were incubated with DMEM containing $2 \%$ BSA and $10 \mathrm{mg} / \mathrm{ml} 1,1^{\prime}$-dioctadecyl-3,3,3',3'-tetramethylindocarbocyanine perchlorate-labeled acetylated LDL (DiI-AcLDL; Biogenesis, Mill Creek, WA) at $37^{\circ} \mathrm{C}$ for $2 \mathrm{~h}$ before fixation. After fixation, the sample was incubated with specific primary antibodies at $4^{\circ} \mathrm{C}$ overnight, followed by staining with secondary antibodies conjugated to Alexa Fluor 568 or Alexa Fluor 488 (Invitrogen). The nuclei were counterstained with the mounting medium Hoechst 33258 (Lonza). Fluorescence images were collected by a (confocal) fluorescence microscope (Olympus FV1000D and Leica AF6000).

\section{Electron Microscopic Observation}

CCT-membranes were fixed and embedded in epoxy resin (Epon 812) as described previously. ${ }^{23}$ Ultrathin sections from the tissue blocks embedded in Epon 812 were contrasted with saturated aqueous solutions of uranyl acetate and lead citrate, and examined with a transmission electron microscope (H7650, Hitachi-High Technologies, Tokyo, Japan).

\section{In Vitro Differentiation Assay}

Cell differentiation was induced by incubation with appropriate differentiation media according to the manufacturer's manual (Mesenchymal Stem Cell Functional Identification kit (SC-010) and Neural Lineage Functional Identification kit (SC-028); R\&D Systems). For adipogenic differentiation, cells were incubated with $\alpha$ MEM (Gibco, Carlsbad, CA) containing hydrocortisone, isobutylmethylxanthine, and indomethacine, and $10 \% \mathrm{FBS}$ at $37^{\circ} \mathrm{C}$. After $7-14$ days of incubation, cells were fixed and stained with Oil Red O (Nacalai Tesque, Kyoto, Japan) or boron-dipyrromethene (BODIPY; Adipocyte Fluorescent Staining kit, Cosmo Bio, Tokyo, Japan). Adipogenesis-specific genes were immunostained using antiFabp4 antibody. For osteogenic differentiation, cells were incubated with $\alpha$ MEM supplemented with ascorbate-phosphate, $\beta$-glycerophosphate, and recombinant human BMP-2, and $10 \% \mathrm{FBS}$ at $37^{\circ} \mathrm{C}$. After 14-21 days, cells were stained with alizarin red (Sigma-Aldrich) or anti-osteopontin antibody (R\&D Systems). For chondrogenesis, cell pellets were incubated in serum-free DMEM/F-12 (Gibco) containing dexamethasone, ascorbate-phosphate, proline, pyruvare, and recombinant human transforming growth factor $\beta 3$ (TGF$\beta 3$ ), at $37^{\circ} \mathrm{C}$. After $17-21$ days, pellets were stained with anticollagen 2 (R\&D Systems). For neurogenic differentiation, cells were pre-treated with base medium (DMEM/F-12 plus N-2 Max Media supplement (R\&D Systems)) supplemented with recombinant human fibroblast growth factor and human epidermal growth factor for $48 \mathrm{~h}$ on plates coated with poly-L-ornithine and fibronectin. Then, the medium was switched to differentiation medium (base medium plus insulin-like growth factor 1 (IGF-1), FBS). After 7-10 days of incubation, cells were fixed and stained with each of the following antibodies; anti-nestin antibody, anti- $\beta 3$-tubulin antibody, anti-marker O4 antibody, or anti-S100 $\beta$ antibody. The in vitro vascular formation assay was carried out as described previously. ${ }^{23,26}$ Briefly, cells and/or mouse thoracic aorta rings were enclosed in Matrigel (BD Biosciences) and incubated with EMB medium (Lonza) containing $20 \mathrm{ng} / \mathrm{ml}$ VEGF. After the indicated incubation time, the cells were extracted and applied to RT-PCR analysis. Some samples were fixed and observed by electron microscopy or immunostaining. ${ }^{23}$

\section{In Vivo Differentiation Assay}

The skeletal muscle injury model, cardiotoxin (SigmaAldrich; $100 \mu \mathrm{l}$ of $0.25 \mathrm{mg} / \mathrm{ml}$ in saline per mouse) was injected into the gastrocnemius of SCID mice (age 8-10 weeks, male). At $4 \mathrm{~h}$ after the surgery or skeletal damage, DsRed-expressing cells $\left(1 \times 10^{5}\right.$ cells in $200 \mu \mathrm{l}$ saline) were injected into the ischemic or damaged muscles. At 2-3 weeks after cell transplantation, the vascular intraluminal endothelial layer was 
stained by the infusion of fluorescein isothiocyanate (FITC)conjugated Griffonia simplicifolia (GSA) lectin (Vector Laboratories, Burlingame, CA; $0.5 \mathrm{mg} / \mathrm{ml}$ saline; $300 \mu \mathrm{l} /$ mouse) via the tail vein just before euthanasia, as described previously. ${ }^{23}$

\section{Statistical Analysis}

Unless otherwise indicated, all data represent means \pm s.e.m. An unpaired two-tailed Student's $t$-test was used to determine the significance of any differences between two group means.

\section{RESULTS}

\section{Isolation and Characterization of Adventitial CPCs and} cECs

Two weeks after wire-mediated injury in femoral artery, enhanced angiogenesis was observed around the injured femoral artery and on the CCT. Microvessels were observed at high density in the CCT membrane (Figure 1a). Most NG2-positive cells were observed as mural cells just outside the lectin-stained endothelial tube (Figure 1b), suggesting that NG2 is a good marker for the isolation of microvascular PCs from the CCT-membrane sample. Single cells within the CCT membrane were dispersed and cell lines positive for PC and EC markers (NG2 and CD146, respectively) were generated using an immunomagnetic cell sorting system as described in Materials and Methods. Although CD146 are proposed for detection of ECs such as capillary ECs, ${ }^{27} \mathrm{CD} 146$ is not completely EC-specific, occuring in PCs and smooth muscle cells (SMCs) at low level..$^{28,29}$ Therefore, to obtain cECs, $\mathrm{CD} 146^{+}$cells from colonies showing a cobblestonelike monolayer appearance were selected. After immortalization and subcloning, six $\mathrm{CPC}$ and three cEC lines were obtained from tsSV40Tg mice.

Morphologically, all cPCs appeared to be spindle-fiber shaped and showed a hill-and-valley appearance at confluence (Figure 1c). To confirm the PC phenotype, we examined the genetic profile of cPCs by RT-PCR. During long-term culture, ie, 30 passages, cPCs maintained the expression of $\mathrm{PC}$-specific marker genes and proteins including NG2, PDGFR $\beta$, calponin, and $\alpha \mathrm{SMA}$, but not EC-specific markers such as von Willebrand factor (vWF) and Flk1 genes (Figure 1d and Figure 2). When cPCs were incubated with the thoracic aorta ring in 3D Matrigel, they migrated and attached around the sprouting endothelial tubes to form capillary-like structures (Figures 1 e and f).

\section{In Vitro Angiogenic Activities of CECs and CPCs}

cECs grew in a monolayer showing a cobblestone appearance at confluence (Figure 3a), and demonstrated stable gene expression of EC markers such as vWF and Flk1, but not aSMA (Figure $3 \mathrm{~b}$ ). Endocytosis and lectin-binding activity are widely exploited to identify ECs in culture. ${ }^{30}$ cECs maintained the ability to endocytose DiI-Ac-LDL and bind GSA lectin (Figure 3c). cECs formed endothelial tube-like structures in Matrigel in the presence of VEGF (Figure 3d). In contrast, cPCs (clone \#6) formed cell clusters and in part small funicular structures in Matrigel (Supplementary Figure 1). When cPCs were co-incubated with cECs, cPCs attached around the cEC tubes to form capillary-like structure (Supplementary Figure 1). The morphological and functional features of these cells were well maintained for long-term culture (more than 30 passages). This suggests that these cells may serve as a good model to study angiogenesis, especially the interaction between cECs and cPCs.

\section{Capillary PCs with Bipotential Mesenchymal and Neuronal Pluripotency}

To select multipotent cPCs among the six established cPC lines, we screened cell lines for their adipogenesis differentiation capacity. Three of the $\mathrm{cPC}$ lines demonstrated multipotency. For further study, we investigated the characteristics of cells from one cPC line (clone \#3 cPCs, termed capillary mPCs) that exhibited the highest multipotency among these three cell lines; clone \#6 cPCs, which had no multipotent properties, was used as the control differentiated PCs, termed cPC6 without specific specification. mPCs were cultured at $37^{\circ} \mathrm{C}$ with the appropriate differentiation medium for the indicated periods. For the adipogenesis assay, most of the cells $(\sim 95 \%)$ were stained with the adiposespecific marker Fabp4 and accumulated small oil droplets after the 7-day induction period (Supplementary Figure 2a). Furthermore, after longer (14-day) incubation, these cells differentiated into mature adipocytes, with enlarged oil droplets (Figure 4a). Differentiation toward osteoblasts and chondrocytes was also observed when mPCs were exposed to differentiation stimuli for 3 weeks. In the osteogenesis assay, the osteoblast-specific marker, osteopontin was initially expressed at 7 days (Supplementary Figure 2b) and obvious calcium accumulation was observed after 21 days of incubation (Figure 4b). For chondrogenic differentiation, mPCs were incubated under floating culture conditions, and the cell pellets expressed the chondrocyte-specific marker collagen II (Figure 4c).

Interestingly, mPCs displayed broad and effective differentiation capacity, giving rise to not only the mesodermic lineage but also the neuronal cell lineage. Nestin is well known as a marker for neuronal stem cells. A few cells of control cPC6 were stained with nestin, but most of the cells were stained in mPCs although the staining was weak (Supplementary Figures $2 \mathrm{c}$ and $\mathrm{d}$ ). When mPCs were incubated for $48 \mathrm{~h}$ with neural maintenance medium, the immunostaining of nestin was getting stronger (Supplementary Figure 2e). Upon additional incubation with neural differentiation medium containing IGF for 7 days, these nestin ${ }^{+}$cells differentiated to marker $\mathrm{O}^{+}{ }^{+}$oligodendrocytes (78.1\%), S100 $\beta^{+}$schwann cells/astrocytes (17.1\%), and $\beta 3$ tubulin $^{+}$neurons $(2.8 \%$; Figures $4 \mathrm{~d}-\mathrm{f})$, and glial fibrillary acidic protein $(\mathrm{GFAP})^{+}$astrocytes (12.4\%; Supplementary Figure 2f). 

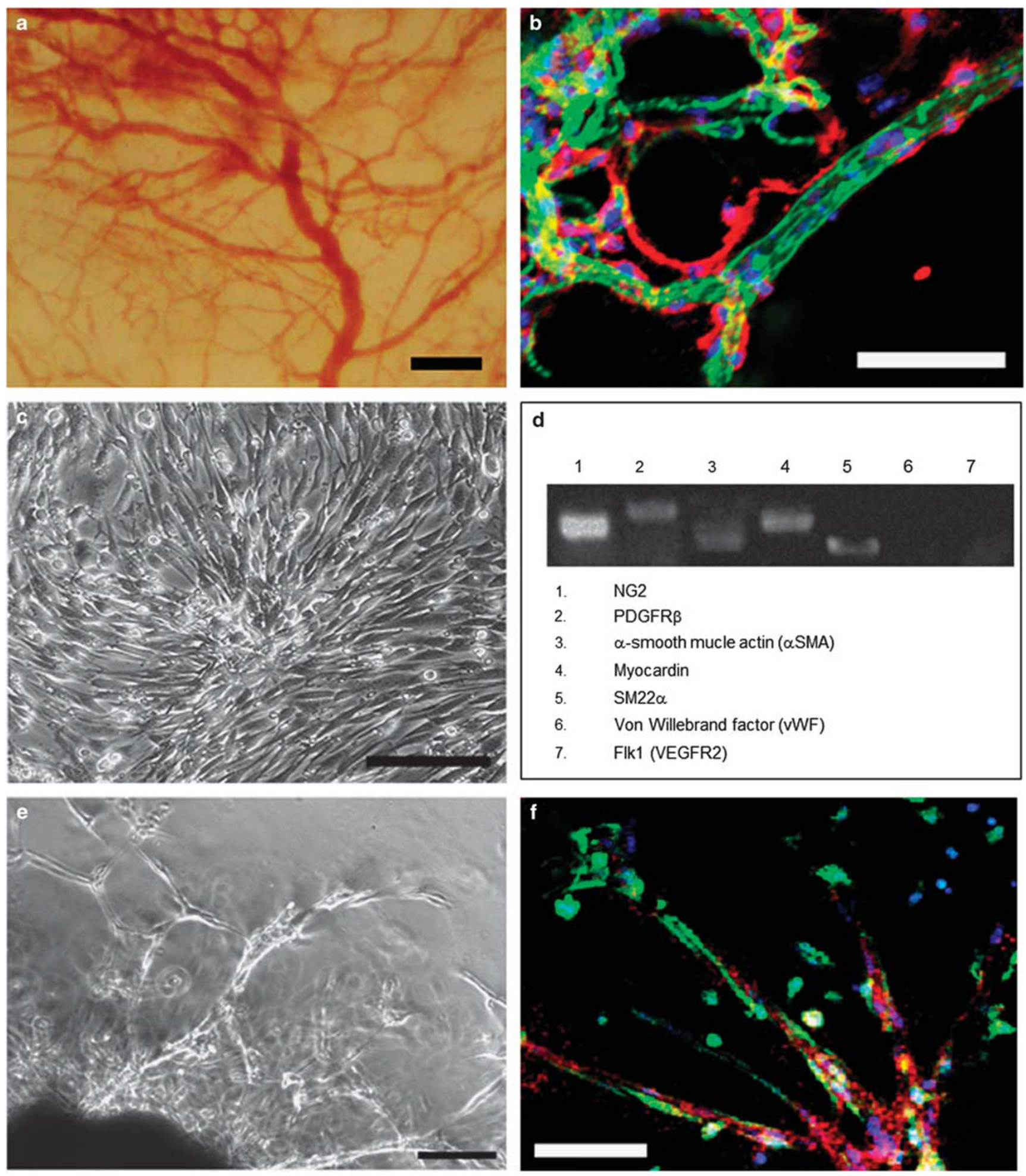

Figure 1 Characteristics of capillary-derived pericytes (cPCs). (a) Numerous microvessels were distributed on the collagen-coated tube (CCT). (b) Most NG2-positive cells (red) were located adjacent to the FITC-conjugated lectin-bound endothelial tubes (green) of microvasculature in the CCT membrane. Nuclei were counterstained with Hoechst 33258. (c) At confluence, cPCs developed a classic hill-and-valley morphology. (d) RT-PCR shows the expression of typical pericyte-specific markers (1-5) but not endothelial cell markers (6 and 7) in cPCs. (e and f) GFP-expressing cPCs (green) were co-incubated with aorta rings in Matrigel. CPCs were attached around the CD31-stained endothelial tube (red) to form capillary-like structures. Scale bars, $50 \mu \mathrm{m}$ (a and $\mathbf{b})$ and $100 \mu \mathrm{m}(\mathbf{c}, \mathbf{e}$, and $\mathbf{f})$. 

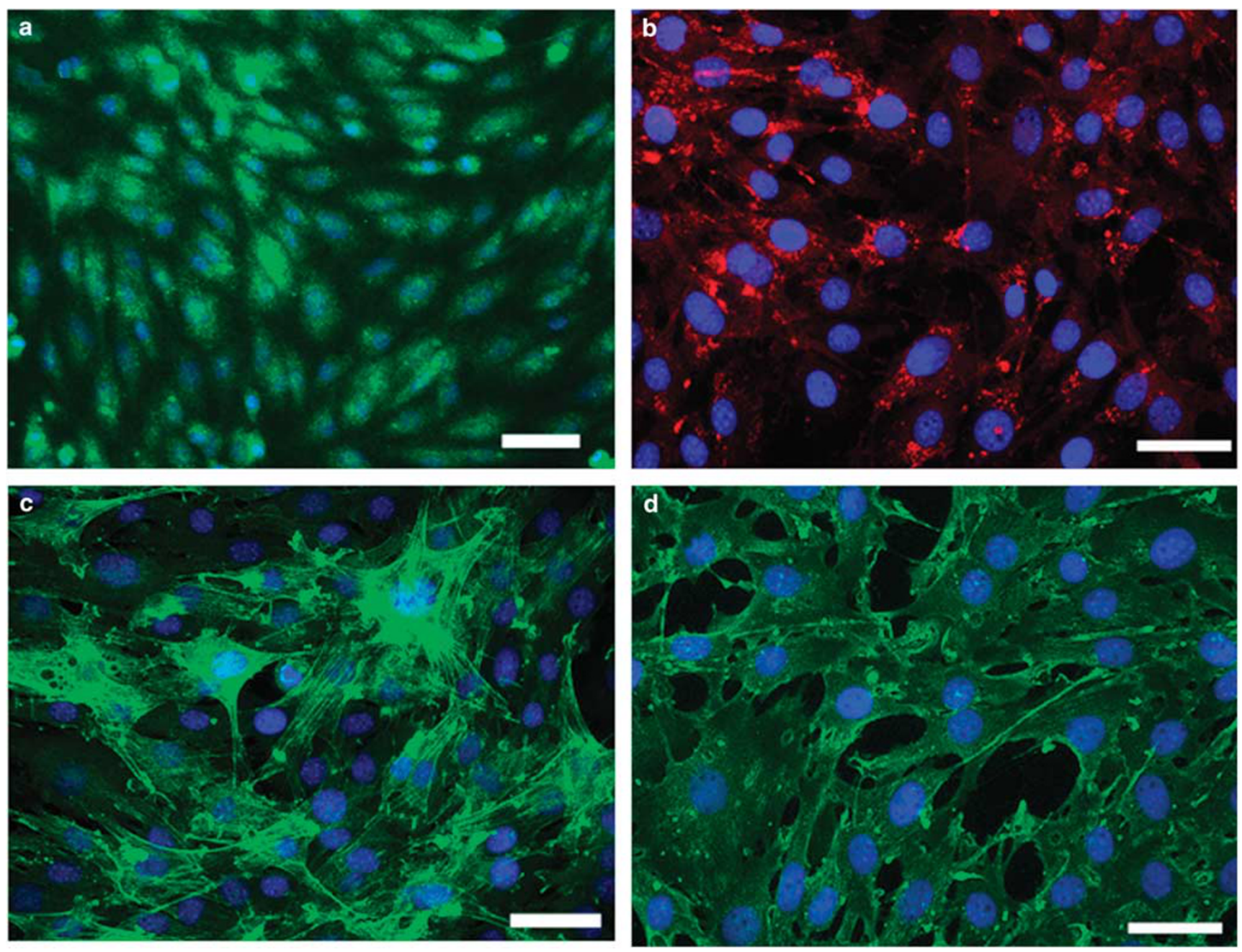

Figure 2 Expression of pericyte markers in CPCs. After the cells reached to confluent, the cells were fixed and immunostained with antibodies against NG2 (a), PDGFR $\beta$ (b), $\alpha$ SMA (c), and calponin (d). Nuclei were identified by Hoechst 33258 (blue). Scale bars, $50 \mu \mathrm{m}$.

The immortalized PCs including mPCs, subcultured more than 30 passages were well grown at constant proliferation rate under low temperature $\left(33^{\circ} \mathrm{C}\right)$ culture condition (Figure 5a). When cPC6 were incubated at temperatures $>37^{\circ} \mathrm{C}$, the tsSV40 is degraded and the cell proliferation was gradually reduced (data not shown). In contrast to cPC6, when $\mathrm{mPCs}$ (both short-term (20 passages) and long-term (40 passages) cultured cells) were subcultured at $37^{\circ} \mathrm{C}$, the proliferation potency was well maintained at least 10 passages (Figure 5a). After mPCs were incubated in the differentiation mediums for adipogenesis and neurogenesis, Fabp4-positive adipocytes and marker O4-positive oligodendrocytes were estimated by flow cytometiry. As shown in Figure 5b, the differentiation efficiency of adipogenesis and neurogenesis of mPCs were $\sim 70$ and $55 \%$, respectively. Importantly, the differentiation efficieny of both long-term and short-term cultured mPCs was similar. Therefore, we confirmed that main characteristics of mPCs were well mainteined for longterm culture condition.

\section{mPCs Differentiate Into ECs and Form Capillary-Like Structures}

In contrast to cPC6 cells (Supplementary Figure 1), mPCs appeared to be connected by thicker projections, forming capillary-like structures under 3D-Matrigel culture conditions in the presence of VEGF (Figure 6a). This feature was not observed when MPCs were cultured without VEGF (data not shown). Ultrastructural analysis of gel matrices demonstrated that the accumulated cells formed tube-like structures; however, these capillary-like structures were somewhat immature, the tubular cell-cell connections were loose, and their walls were partially covered by other cells (Figure 6b). After 3 days of incubation with VEGF, the medium was exchanged to flesh medium containing TGF $\beta$ instead of VEGF. The vessel-like structures formed were further enlarged (Figure 6c), constituting CD31-positive tubes fully covered by $\alpha \mathrm{SMA}$-positive cells (Figure $6 \mathrm{~d}$ ). In parallel assays, RT-PCR analysis of these cells in gel demonstrated that VEGF induced the expression of the mature EC marker vWF, and 

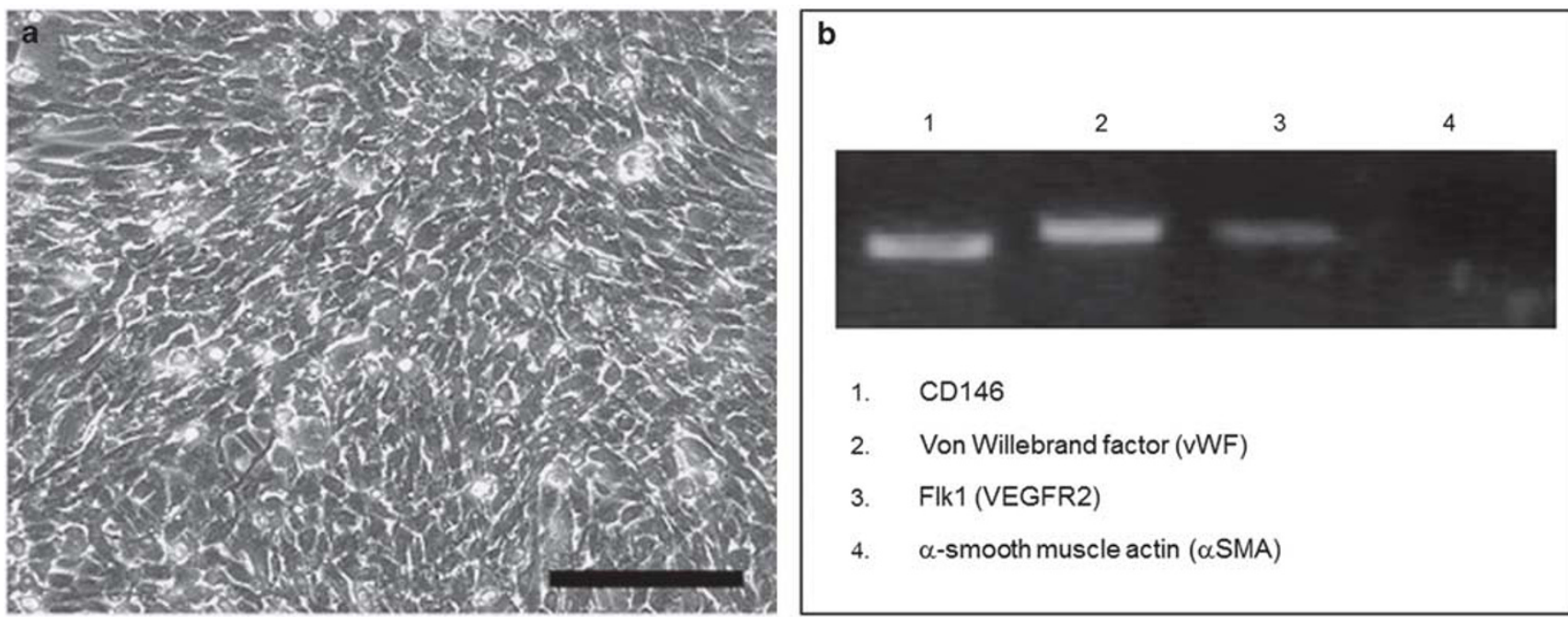
1. $\mathrm{CD} 146$
2. Von Willebrand factor (VWF)
3. Flk1 (VEGFR2)
4. $\alpha$-smooth muscle actin ( $\alpha$ SMA)
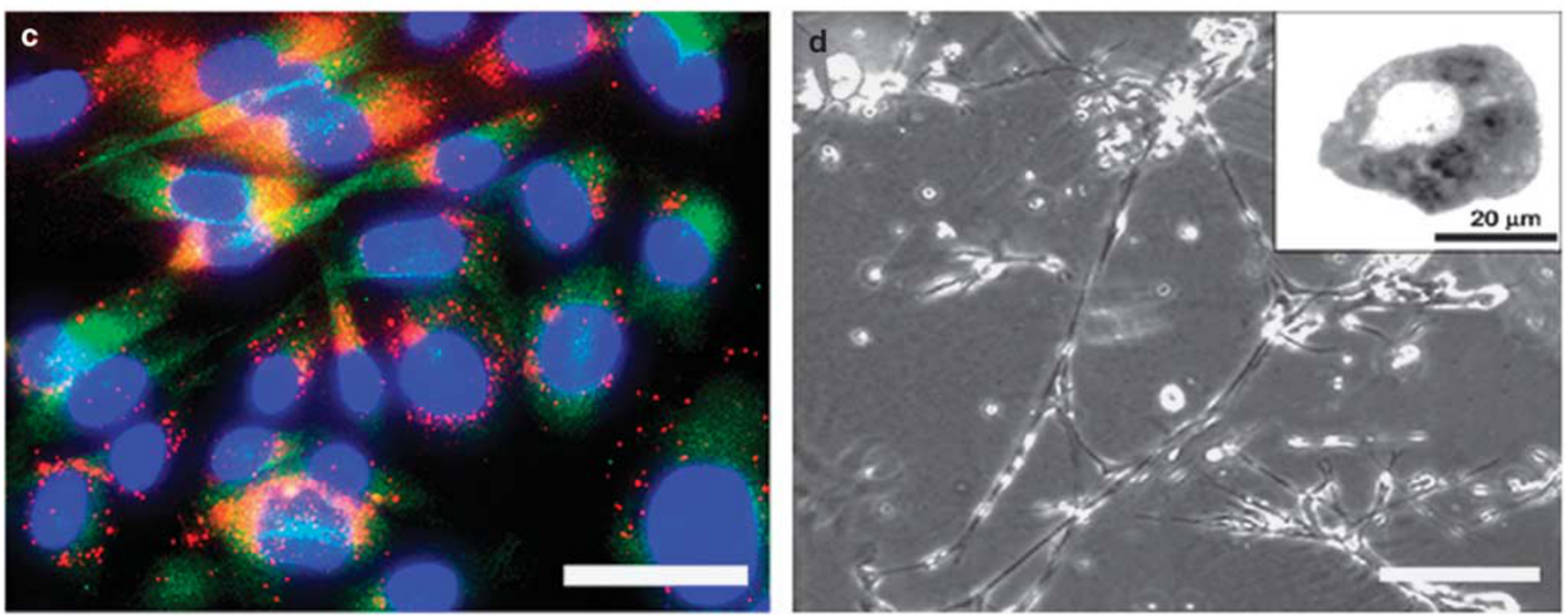

Figure 3 Characteristics of capillary-derived endothelial cells (cECs). (a) cECs developed a cobblestone morphology at confluence. (b) Total RNA of CECs was analyzed by RT-PCR and gene expression of the indicated endothelial markers (1-3) but no pericyte marker (4) was observed. (c) cECs were incubated with Dil-labeled Ac-LDL and FITC-conjugated GSA lectin. CECs maintained the ability to endocytose Ac-LDL particles (red) and bind to lectin (green). Nuclei were visualized by DAPI staining (blue). (d) cECs were incubated with VEGF in Matrigel, and formed peculiar endothelial tubes (EC tubes). Axial view of the formed EC tube is shown (inset). Scale bars, $100 \mu \mathrm{m}$ (a and $\mathbf{d}$ ) and $30 \mu \mathrm{m}$ (c).

enhanced $\alpha$ SMA expression (Figures 6e and f). These data demonstrate that mPCs differentiate into both ECs and PCs or SMCs, and have an ability to form mature vessels on their own.

\section{In Vivo Regeneration Potency of mPCs}

We then determined whether the broad multipotency and potent proangiogenic activity of mPCs results in the improved regeneration in damaged tissues or ischemic tissues in vivo. For this purpose, DeRed-expressing mPCs were transplanted intramuscularly into immunodeficient mice subjected to cardiotoxin-mediated muscle injury. Two weeks after transplantation into damaged skeletal muscles, regenerating centrally nucleated myofibers that were stained with DsRed were observed, and interestingly, numerous capillaries within the regenerating skeletal muscle area also showed DsRed staining (Figures 7a and b). At higher magnitude view, transplanted cells were engrafted into capillary, mostly composed as either capillary ECs or perivascular cells (Figures $7 \mathrm{c}$ and $\mathrm{d}$ ).

\section{Comprehensive Analysis of Gene Expression Profile of mPCs}

Cloned mPCs and other cPCs stably maintain their features. Therefore, these cell lines, which have different multipotent activities, would be very useful to examine the characteristics of adventitial mPCs. The immortalized cPCs (mPCs and cPC6) were assayed for their antigen expression by flow cytometry and RT-PCR, and showed the expression of PC markers (NG2, $\alpha \mathrm{SMA}$, and CD146), but not endothelial 

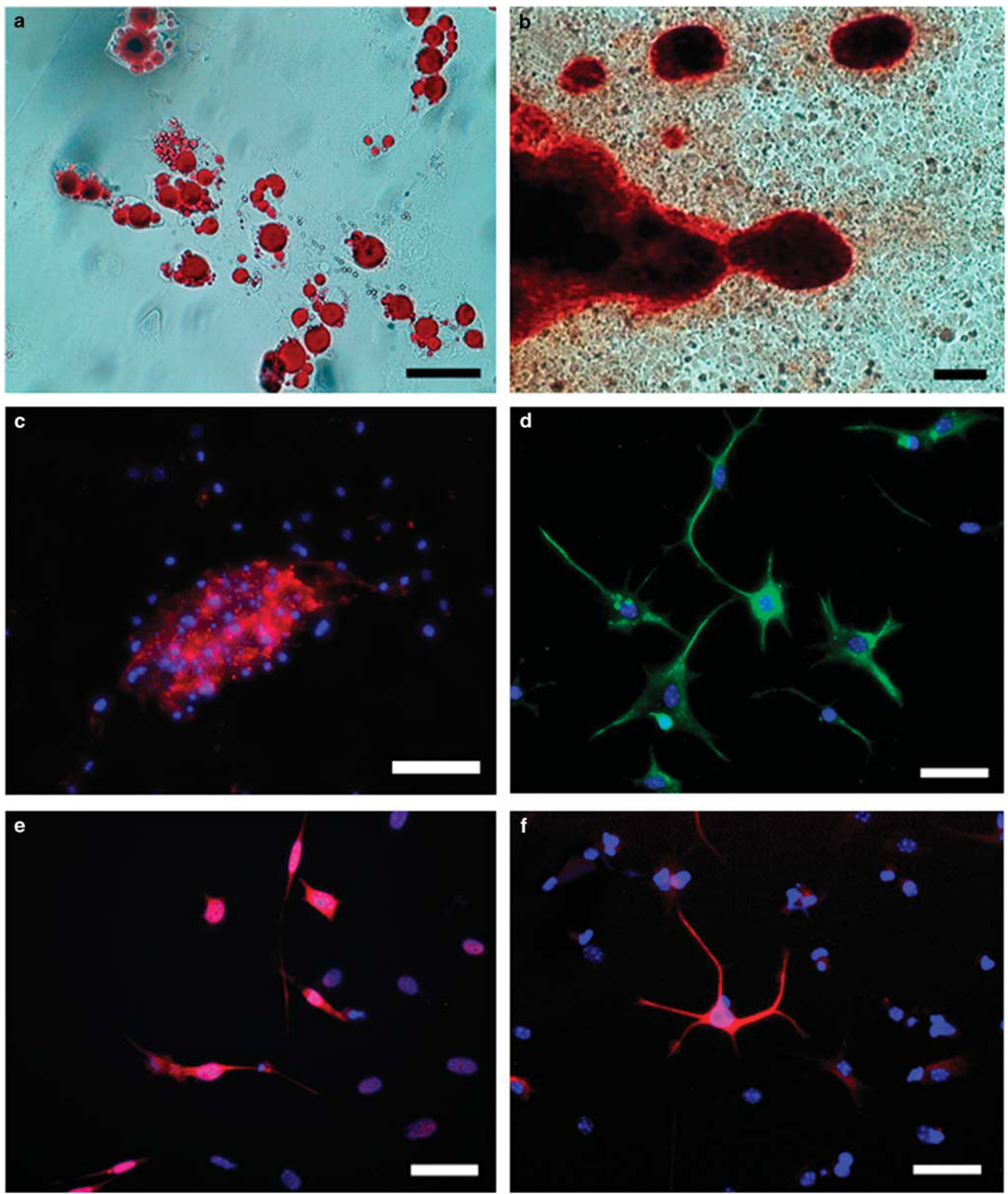

Figure 4 Multipotency of cPCs. Under appropriate differentiation conditions, multipotent PCs (mPCs), one of the established cPC lines (clone \#3 PC), displayed broad differentiation capacity. MPCs gave rise to cells of mesodermal lineage such as Oil-Red-stained adipocytes (a), alizarin red-stained osteoblasts (b), and collagen II-immunostained chondrocytes (c). mPCs also differentiated into neuronal cells, immunostained with each oligodendrocyte marker $\mathrm{O} 4$ (d), $\mathrm{S} 100 \beta$ (e), and $\beta 3$-tubulin (f). Nuclei were identified by Hoechst 33258 (blue). Scale bars, $50 \mu \mathrm{m}$. 


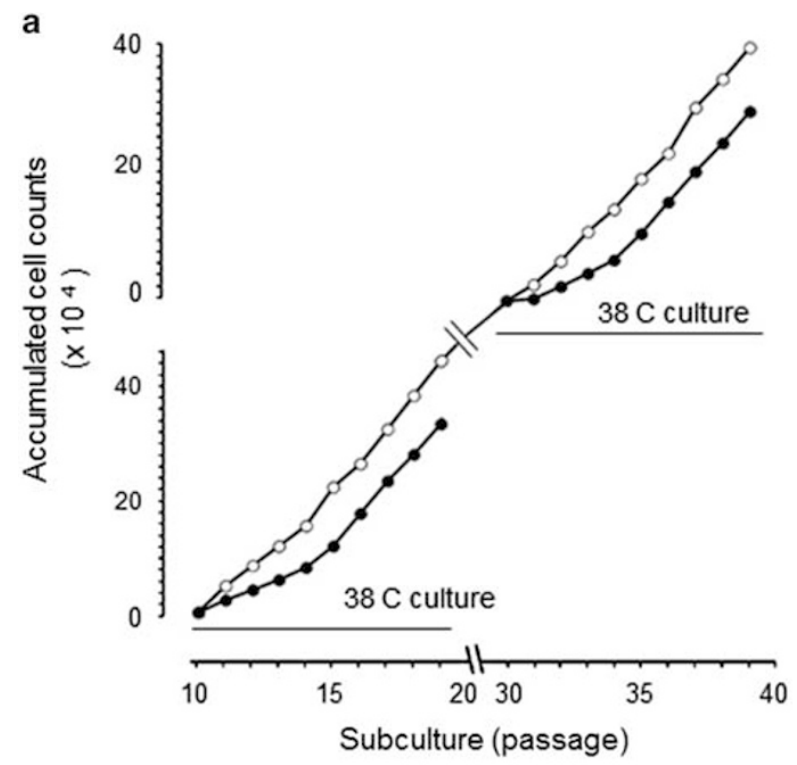

b

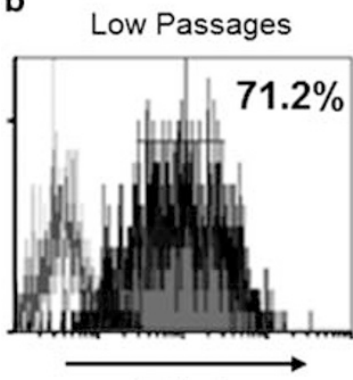

Fabp4

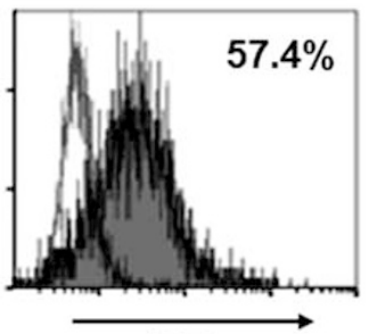

MO4
High Passages

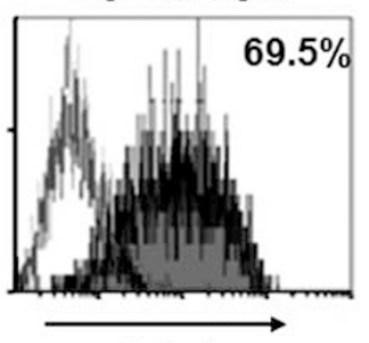

Fabp4

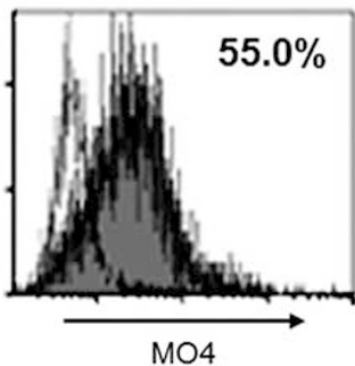

$\mathrm{MO} 4$
Figure 5 Differentiation efficiency of $\mathrm{mPCs}$. (a) Cumulative cell numbers during passage under culture at different temperature. Culture of immortalized cells was maintained at $33^{\circ} \mathrm{C}$ (open circle). The constant growth rate is maintained for more than 50 passages. In parallel with this maintenance culture, the cells at indicated passage were subcultured at $38^{\circ} \mathrm{C}$ (closed circle). (b) The cells which were subcultured at low (20) and high (40) passages were incubated with adipo- and neuro-differentiating medium for 7 days, and differentiated adipocytes or oligodendrocytes were determined by flow cytometry using specific antibodies against Fabp4 and marker O4, respectively. Negative control was obtained using isotype-matched nonimmune antibodies.

markers were well maintained in both mPCs and cPC6 (Figures $8 \mathrm{a}$ and $\mathrm{b}$ ). To date, no specific marker is available to define the mPC phenotype from among other PCs. ${ }^{8,9}$ Therefore, it is interesting to compare gene expression levels between mPCs and non-multipotent cPC6 cells. mPCs expressed MSC markers (CD29, CD44, CD105, CD106, and Sca1), but not endothelial or hematopoietic markers including CD31, CD34, CD11b, and CD45 (Figure 8c). However, these markers were expressed in both mPCs and cPC6 cells (Figure 8b). We performed microarray analysis of gene expression profiles in mPCs and cPC6 cells. The expression levels of some MSC marker genes were increased in mPCs (Table 1). Interestingly, NSC marker genes such as nestin were relatively selective for mPCs compared to cPC6 (Table 1).

\section{DISCUSSION}

\section{mPCs Derived from Pathological Neovasculature}

In general, cellular surface antigen markers are frequently used as the gold standard for the selection of specific cells of interest within tissues. Cellular markers currently used for PCs, such as NG2 and PDGFR $\beta$, are not PC-specific and differ depending on the tissue. ${ }^{4,31}$ NG2 is a frequently utilized PC marker; however NG2-expressing cells also include oligodendrocytes, skeletal myoblasts, cardiomyocytes, and some NSCs. ${ }^{4}$ Thus, these markers are only useful for the isolation of PCs from restricted capillary-rich tissue. Recently, we developed a novel in vivo angiogenesis assay using the CCT membrane. ${ }^{23}$ As demonstrated in Figure 1, we found that NG2 is a good marker for PCs in the CCT membrane. In this study, we isolated NG2-positive cells from growing microvessels in the CCT-membrane. Finally immortalized capillary PCs were developed from the adventitial vasa vasorum of the injured femoral artery.

Adventitial vasa vasorum neovascularization mediates vascular remodeling, although the mechanisms that mediate vascular remodeling have not been fully elucidated. ${ }^{12} \mathrm{~A}$ number of studies have demonstrated that the adventitia provides a perivascular niche for stem/progenitor cells that contribute to vascular repair, fibrosis, and atherosclerosis. ${ }^{18,32}$ Indeed, the number of mPCs increases in the adventitia of injured femoral arteries, and these cells participate in the restenotic response to arterial injury. ${ }^{33,17}$ Along with these findings, we established mPCs, which have unique features as discussed below, at a relatively high proportion among immortalized PC lines (three of six lines). Therefore, it is suggested that the $\mathrm{mPC}$ is a specific PC subtype associating with the growing adventitial vasa vasorum and contributes to vascular remodeling.

Numerous studies demonstrated that PCs have seveal different developmental origins, consisting of heterogenous populations. ${ }^{4}$ In this study, series of cPC cell lines, which have different degree of multipotency clearly demonstrated the existence of heterogenous PC populations, at least mutipotent PCs and non-mPCs. Recently, CD146 has been utilized as marker for mPCs. ${ }^{3}$ However, CD146 is not a specific marker for certain mPCs, and no specific markers to isolate multipotent cells prospectively from heterogenous PC populations have been identified by current research. ${ }^{4}$ 

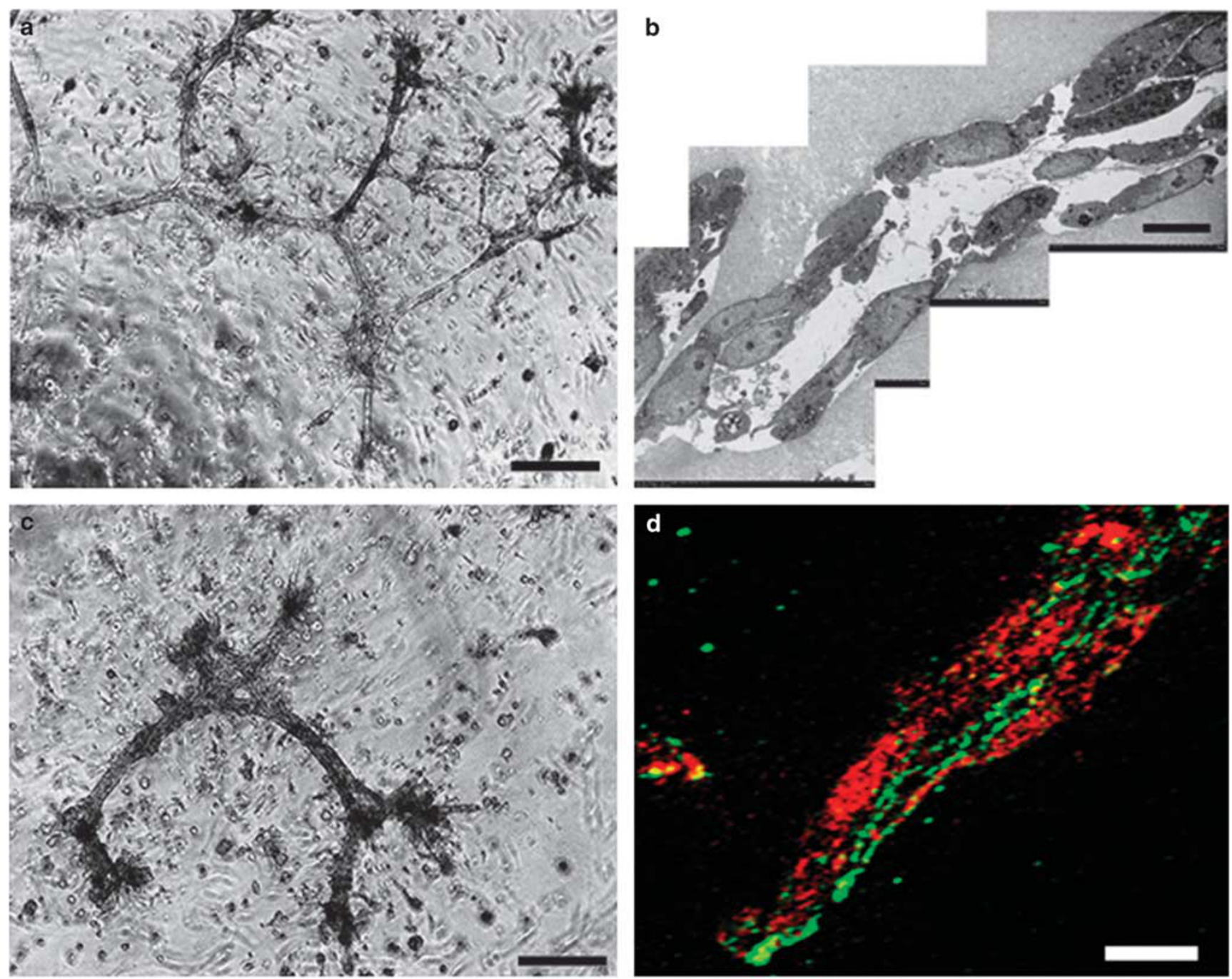

e
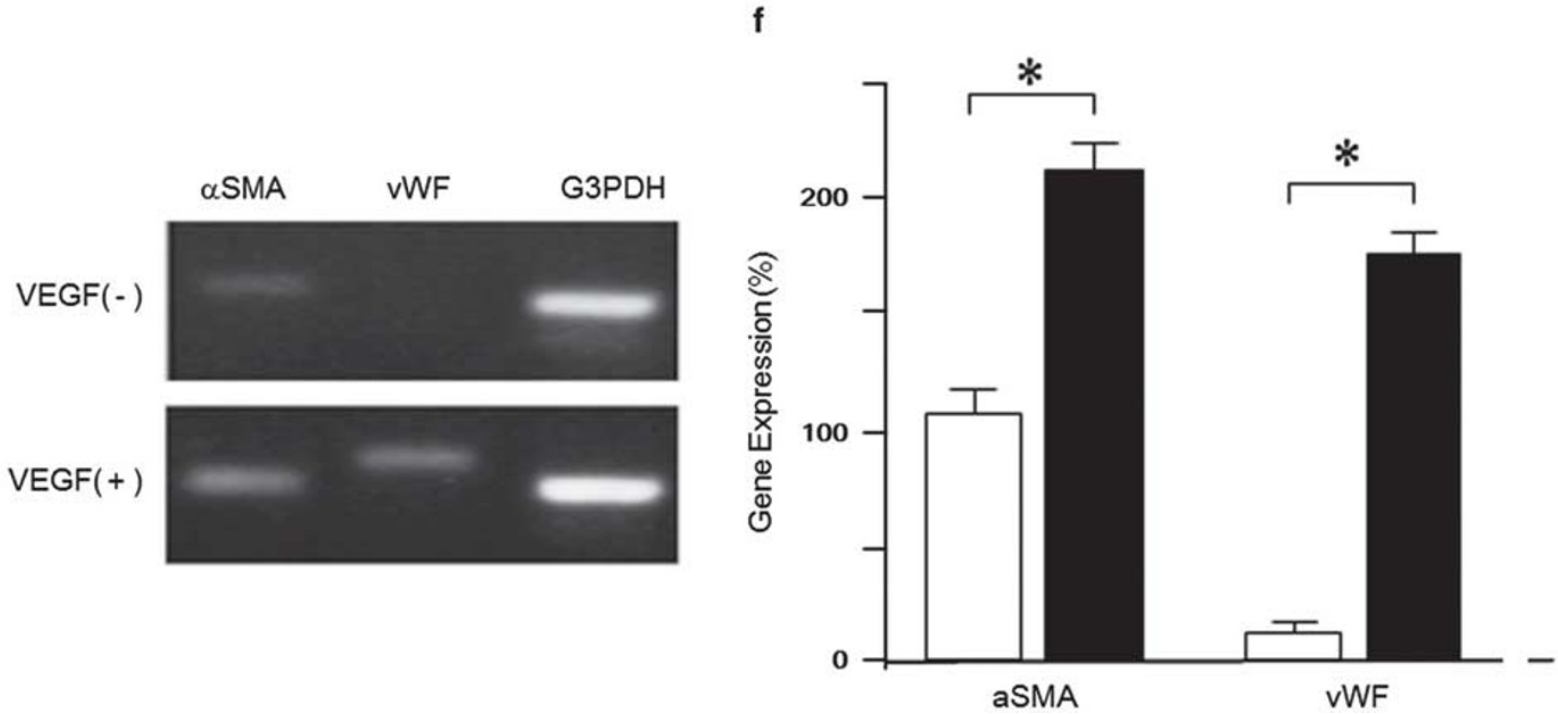

Figure 6 For caption please refer page 1350. 
Therefore, to identify $\mathrm{mPCs}$, researchers have to rely on the lack of markers for other cell lineages including non-endothelial (CD31) and non-hematopoietic (CD34) cells. ${ }^{3}$ In this study, we analyzed gene expression profiles among non-multipotent cPCs, cPC6, and mPCs. Indeed, there were no differences in the expression levels of NG2 and CD146 in mPCs and non-multipotent cPC6 (Figure 8 and Table 1).

At this time, it is uncertain whether the ratio of mPCs (three of six $\mathrm{CPC}$ ) within vasa vasorum in the injured vessels is relatively high or not. The ratio of $\mathrm{mPCs}$ among all PCs within microvessels might be varied depend on the kinds of
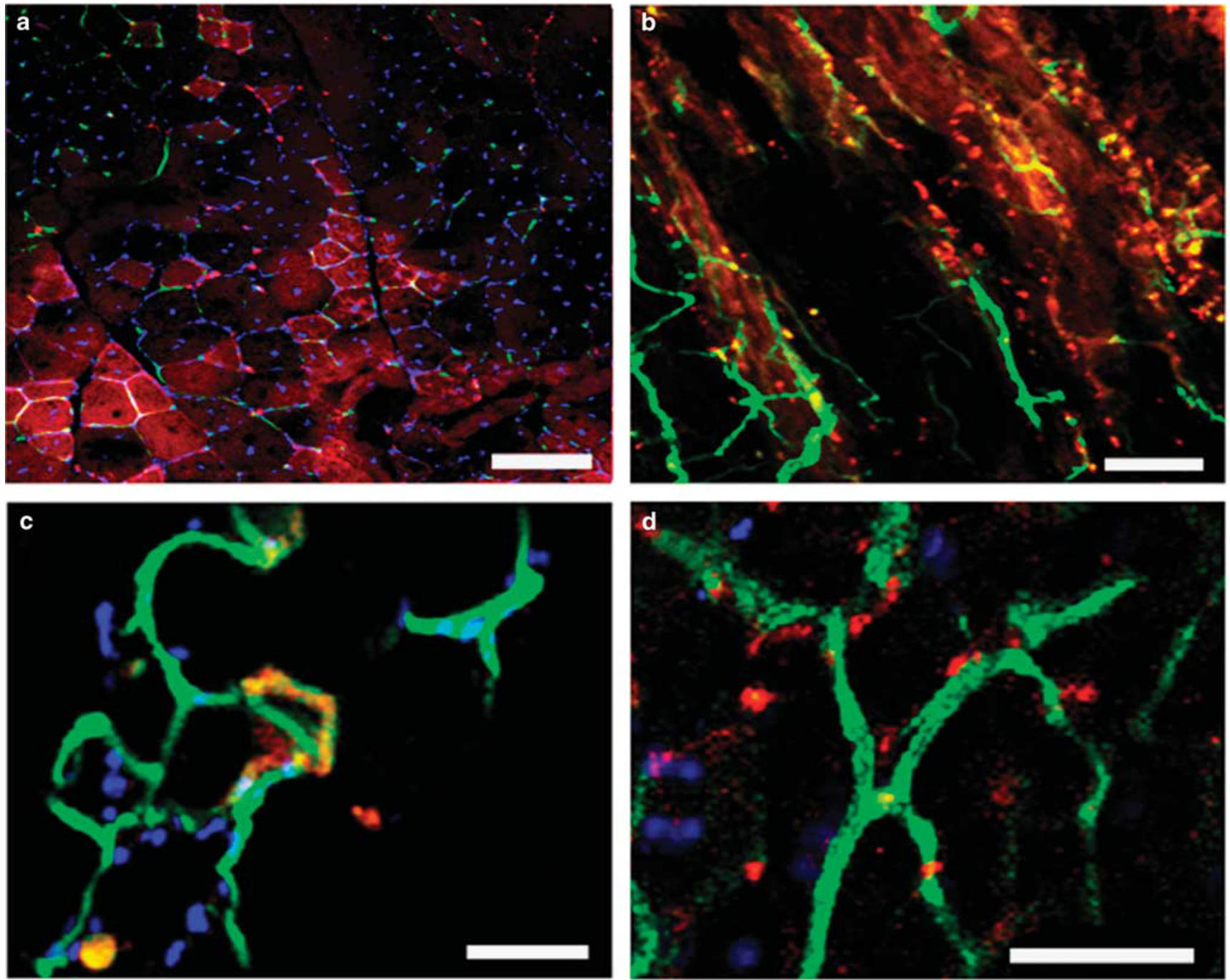

Figure 7 In vivo regenerative capacity of mPCs. (a) After gastrocnemius of SCID mouse were damaged by cardiotoxin, Ds-Red-mPCs were transplanted into the damaged muscle by intramuscular injection. After 14 days of cardiotoxin-induced muscle damage/cell transplantation, mPCs were well engrafted into regenerative skeletal muscle, composed of myofibers and capillaries as seen in the long and short axial views, respectively (a and $\mathbf{b}$ ). Confocal microscopic analysis showed that transplantation of mPCs (red) was closely associated with muscular capillary tubes (green) as endothelial and perivascular cells (c and d). Scale bars, $50 \mu \mathrm{m}$ (a and $\mathbf{b}$ ) and $100 \mu \mathrm{m}$ (c and $\mathbf{d}$ ).

Figure $6 \mathrm{mPCs}$ form capillary-like structures. (a) mPCs formed capillary-like structures in Matrigel in the presence of VEGF. (b) Electron microscopic analysis demonstrated that the formed tubule structure was composed of cellular walls with loose intercellular adhesions. (c) When the gels were further incubated with TGF $\beta$ instead of VEGF, the vessels became thicker. (d) In situ immunostaining of Matrigel and confocal microscopic analysis show that the formed vessels are composed of CD31-positive tubules (green) surrounded by $\alpha$ SMA-positive cells (red). (e) Gene expression of $\alpha$ SMA and VWF in the presence or absence of VEGF was estimated by RT-PCR. Glyceraldehyde-3-phosphate dehydrogenase (G3PDH) was used as an internal control. (f) The level of each gene in the absence (open bars) or presence (closed bars) was calculated as the ratio to the density of G3PDH. Values are mean \pm s.e.m. $n=5$, ${ }^{*}<<0.05$. Scale bars, $200 \mu \mathrm{m}$ (a and c), $10 \mu \mathrm{m}(\mathbf{b})$, and $50 \mu \mathrm{m}(\mathbf{d})$. 
a
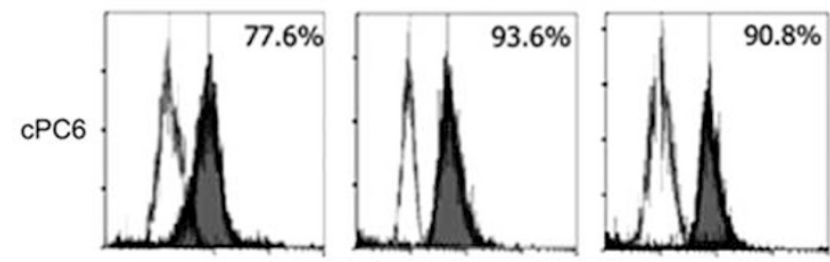

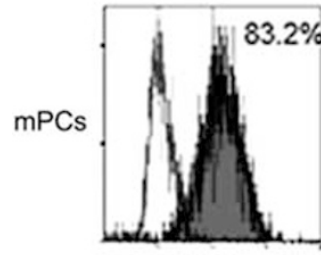

NG2

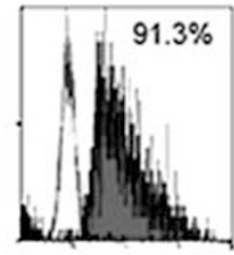

$\alpha$ SMA

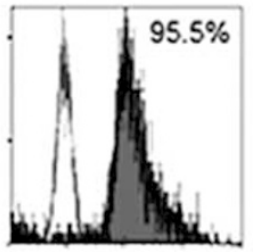

CD146

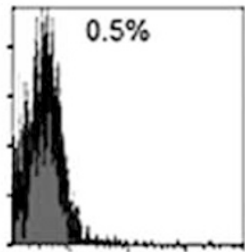

CD31

b
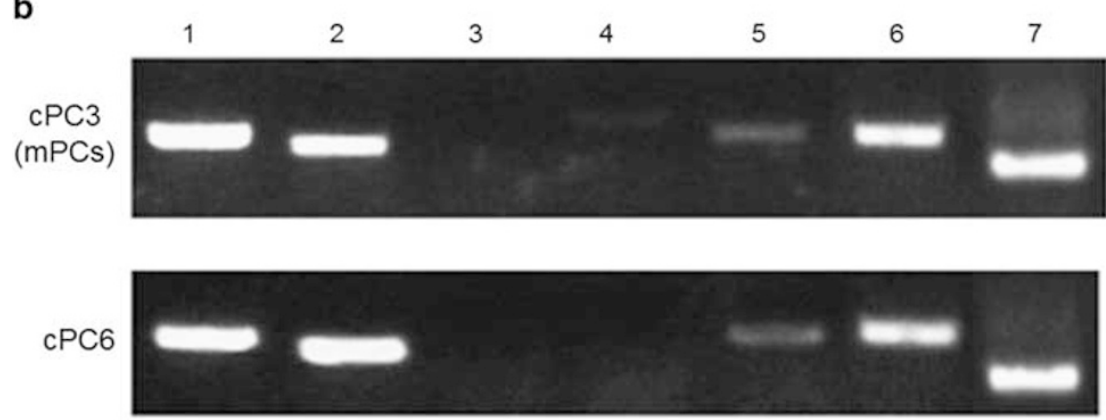

C
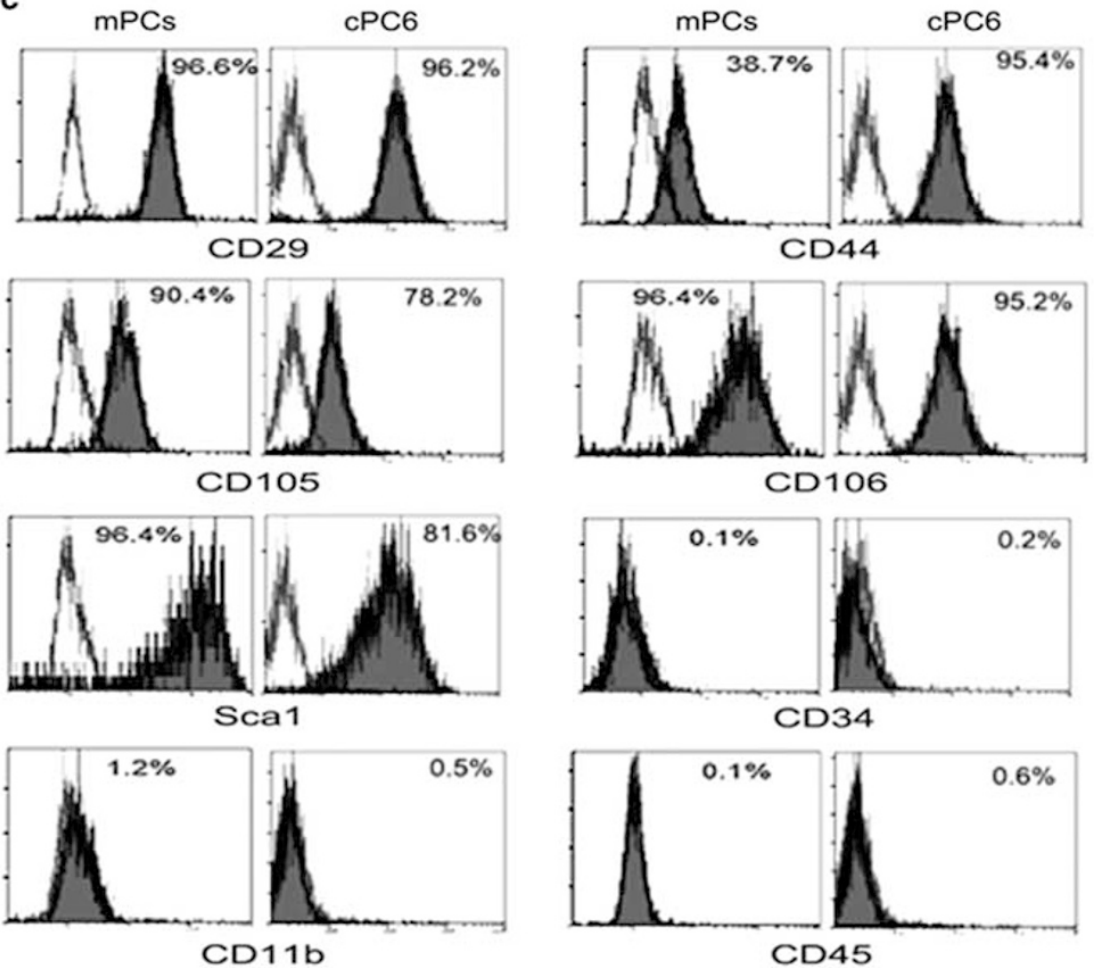

Figure 8 Gene and protein expression profile of mPCs and control cPC6. (a) Histogram shows flow cytometry analysis of cells enriched with pericytesurface markers (NG2, $\alpha \mathrm{SMA}$, and CD146), but not endothelial marker, CD31. Signals for fluorescent isotype lgG are shown in black and antigen-specific signals are shown in closed shaded curves. (b) Expression levels of indicated genes (1. CD146, 2. NG2, 3. vWF, 4. Flk1, 5. PDGFR $\beta$, 6. $\alpha$ SMA, and 7. G3PDH) within each PCs cell lines were determined by RT-PCR. (c) Cell surface markers for mesenchymal stem cells (CD29, CD44, CD105, CD106, and Sca1), and hematopoietic cells (CD34, CD11b, and CD45) of each cell line was determined by flow cytometry. 
Table 1 Comparison of gene expression in CPCs cell lines

\begin{tabular}{|c|c|c|c|c|c|}
\hline Marker & Gene & $\begin{array}{c}\text { GenBank } \\
\text { accession } \\
\text { numbers }\end{array}$ & $\begin{array}{l}\text { CPC3 } \\
\text { (mPCs) }\end{array}$ & cPC6 & $\begin{array}{l}\text { Difference } \\
\text { log2 (ratio) }\end{array}$ \\
\hline \multirow[t]{8}{*}{ PC } & Pdgfrb & NM_008809 & 905 & 540 & 1.68 \\
\hline & Cspg4 (NG2) & NM_139001 & 10 & 35 & 0.29 \\
\hline & Mcam (CD146) & NM_023061 & 57 & 31 & 1.82 \\
\hline & Rgs5 & NM_009063 & 9 & 16 & 0.60 \\
\hline & Des & NM_010043 & 31 & 27 & 1.17 \\
\hline & $\mathrm{Ngfb}$ & NM_013609 & 159 & 142 & 1.12 \\
\hline & Angpt1 & NM_009640 & 76 & 150 & 0.51 \\
\hline & Vim & NM_011701 & 33064 & 29895 & 1.11 \\
\hline \multirow[t]{5}{*}{ EC } & Pecam1 (CD31) & NM_008816 & 2 & 9 & 0.20 \\
\hline & Flt1 (VEGFR1) & NM_010228 & & 16 & \\
\hline & Kdr (VEGFR2) & NM_010612 & 60 & 38 & 1.57 \\
\hline & Vwf & NM_011708 & 8 & 8 & 0.97 \\
\hline & Sele (E-selectin) & NM_011345 & 5 & 5 & 1.12 \\
\hline \multirow[t]{7}{*}{ MSC } & Anpep (CD13) & NM_008486 & 227 & 256 & 0.89 \\
\hline & Itgb1 (CD29) & NM_010578 & 3088 & 1747 & 1.77 \\
\hline & $\mathrm{Cd} 44$ & NM_009851 & 4 & 8 & 0.47 \\
\hline & Nt5e (CD73) & NM_011851 & 6 & 6 & 0.99 \\
\hline & Thy1 (CD90) & NM_009382 & 3 & 13 & 0.25 \\
\hline & Eng (CD105) & NM_007932 & 165 & 116 & 1.42 \\
\hline & Vcam1 (CD106) & NM_011693 & 2831 & 5406 & 0.52 \\
\hline \multirow[t]{3}{*}{ NSC } & Nes & NM_016701 & 155 & 24 & 6.38 \\
\hline & Cxcl12 & NM_013655 & 2969 & 849 & 3.50 \\
\hline & Lepr & NM_010704 & 87 & 103 & 0.84 \\
\hline \multirow[t]{2}{*}{ Other SC } & Ly6a (Sca1) & NM_010738 & 22387 & 6319 & 3.54 \\
\hline & $\mathrm{Cd} 34$ & NM_133654 & 4 & 6 & 0.56 \\
\hline
\end{tabular}

Abbreviations: EC, endothelial cell; MSC, mesenchymal stem cell; NSC, neuronal stem cell; PC, pericytes. Gene expression analysis of CPC cell lines (clone \#3 and \#6) was done using 3D-Gene mouse Oligo chip (Toray). Fold-change difference in gene expression between mPCs (CPC3) and non-multipotent cPCs (CPC6) was expressed as log2 (ratio). Difference ratio $>2.0$ is considered as significant difference (bold).

tissues and the condition of tissues, ie, inflammatory/ regenerative states. The identification of a specific marker to determine stem/progenitor cells among PCs would be crucial in order to clarify the biology of mPCs. Recently, Birbrair et $a l^{34}$ demonstrated that $\mathrm{PC}$ have been identified as a heterogenous cell population, nestin-positive and -negative PCs in skeletal muscle. Interestingly, nestin-positive PCs can differentiate into skeletal muscle and neural cells. ${ }^{35}$ In this study, we found that expression of nestin was relatively selective for mPCs compared to cPC6 (Supplementary Figures $2 \mathrm{c}$ and $\mathrm{d}$ ). Furthermore, the gene microarray analysis demonstrated that expression level of nestin was higher in mPCs, compared to cPC6 (Table 1). Therefore, these data well consist with the previous study. ${ }^{35}$ Therefore, the group of cPC cell-lines, including mPCs, would be a powerful tool to identify specific markers for native mPCs.

\section{mPCs are Capillary-Forming Stem Cells}

A number of studies have demonstrated that vascular resident stem/progenitor cells were observed in small and large vessel walls. ${ }^{15,18,36}$ In addition to their multilineage potential, they exert a potent angiogenic effect through either the adoption of an endothelial- or a PC-like phenotype. Campagnolo et $a l^{37}$ isolated a population of $\mathrm{CD} 34^{+} \mathrm{CD} 31^{-}$progenitor cells from the adventitia of human saphenous vein-derived progenitor cells. Saphenous vein-derived progenitor cells could be cloned in vitro and possessed multipotency for differentiating into mesenchymal cells, including PCs and SMCs. Saphenous vein-derived progenitor cells have PC-like features in mouse hindlimb ischemia, formed cell-cell contacts with ECs, stimulated angiogenesis, and improved flow recovery. Adventitial $\mathrm{CD} 34^{+} \mathrm{CD} 31^{-} \mathrm{CD} 146^{-}$stem cells showed distinct phenotypes from PCs. However, they acquire a PC-like phenotype in the presence of growth factors and contribute to angiogenesis. ${ }^{38} \mathrm{CD} 146^{+} \mathrm{CD} 34^{-} \mathrm{CD} 31^{-} \mathrm{mPCs}$ also act as PCs and contribute to angiogenesis. ${ }^{3,33}$ Recently, vascular resident endothelial progenitor cells (EPCs) were identified by means of a Hoechst-labeled side population. ${ }^{39}$ Vascular resident EPCs differentiate into ECs, and restore blood flow and reconstitute long-term surviving blood vessels.

To our knowledge, ${ }^{8,19,39}$ these vascular resident stem cells can differentiate into either ECs or PCs to promote angiogenesis in vivo, but cannot acquire both kinds of cells to form capillary-like structures. Early studies demonstrated that MSCs formed capillary-like structures, composed of an endothelial tube covered by PCs. ${ }^{40,41}$ Most MSCs prepared in these studies are composed of heterogenous cell populations that may contain endothelial- and PC-progenitor cells or pluripotent stem cells. ${ }^{42}$ In this study, clonal mPCs acquired both endothelial- and PC-like phenotypes in the presence of VEGF and formed capillary-like structure on their own in Matrigel (Figure 6). When mPCs were transplanted into damaged skeletal muscle tissues, mPCs were assembled into a de novo long-lasting functional capillary as endothelial and mural cells in vivo (Figure 7).

\section{mPCs Exhibit Bipotential Pluripotency}

In this study, clonal mPCs exhibit multilineage potential, showing the ability to differentiate in vitro into both mesenchymal and neuronal lineage cells (Figure 4). This transdifferentiation across germ layers has been previously demonstrated in perivascular stem/progenitor cells. ${ }^{19,37,38}$ It is widely believed that MSCs are derived from mesoderm. Recent advances in cellular imaging and lineage tracing techniques indicated that MSCs have several different embryonic origins, such as the neural crest, in addition to mesoderm. ${ }^{43,44}$ Neural crest cells are migratory stem cells that 
are generated along the entire vertebrate axis at the neural plate border, and begin to migrate to the periphery and differentiate into various tissues during development. In adults, stem cells originating from the neural crest show persistent mesodermal and neuronal differentiation potential, and replenish associated tissues. ${ }^{45}$ It is uncertain whether adventitial mPCs originate from neural crest cells. However, the genomic expression profile of mPCs indicated that some NSC markers, including nestin, are dominantly expressed in these cells compared to control cPC6 (Table 1), as discussed previously. Perivascular adipose tissues (PAT) have been considered solely as vessel-supporting connective tissue. A number of recent studies demonstrated that PAT affect the functions of PAT-adjacent vasculature and contribute to vascular remodeling. ${ }^{46,47}$ Adipocytes originally differentiate from adipocyte progenitors and are related to the remodeling of adipose tissues under certain local and general conditions. MSCs residing in the perivascular region depots form and give rise to resident adipocyte progenitors. ${ }^{5}$ In this study, we demonstrate that among the various differentiation potencies, the adipogenesis potential of mPCs is relatively high (Figure 4, Supplementary Figure 2). They can differentiate into adipocytes not only at high ratios but also with a high degree of maturation for differentiation. Adventitial mPCs would represent an adipocyte-progenitor feature for the reconstitution of PAT and provide a useful tool to elucidate perivascular adipose development.

In conclusion, we established immortalized capillary cells (ECs and PCs) derived from pathological neovasculature within the adventitia, using the unique CCT membrane. Especially, we identified mPCs, which have unique multipotent features. Of course, prudent interpretations of the role of these cells should be required as these cell lines were generated by the action of immortalizing the tsSV40. Importantly, genomic expression profile, cellular functions, and immunostaining pattern that are simlar to common features of ECs and PCs were well maintained for long-term culture condition. Therefore, these cloned cell lines would be a useful tool for elucidating the characteristics of mPCs and also for the interaction between ECs and PCs to form capillary structure.

Supplementary Information accompanies the paper on the Laboratory Investigation website (http://www.laboratoryinvestigation.org)

\section{ACKNOWLEDGMENTS}

We thank K Kanno, A Oda, S Takahashi, Y Horikawa, and E Shinokawa for laboratory assistance, and Y. Segawa for secretarial assistance. Funding for this study was provided by a Grant-in-Aid for Scientific Research from the Ministry of Education, Science, Sports, and Culture of Japan (22590820, 25461121); a grant from The Akiyama Life Science Foundation, Suhara Memorial Foundation, and Mitsubishi Pharma Research Foundation.

\section{DISCLOSURE/CONFLICT OF INTEREST}

The authors declare no conflict of interest.
1. Diaz-Flores L, Gutierrez R, Madrid JF, et al. Pericytes. Morphofunction, interactions and pathology in a quiescent and activated mesenchymal cell niche. Histol Histopathol 2009;24:909-969.

2. Armulik A, Abramsson A, Betsholtz C. Endothelial/pericyte interactions. Circ Res 2005;97:512-523.

3. Crisan $M$, Yap $S$, Casteilla $L$, et al. A perivascular origin for mesenchymal stem cells in multiple human organs. Cell Stem Cell 2008;3:301-313.

4. Armulik A, Genove G, Betsholtz C. Pericytes: developmental, physiological, and pathological perspectives, problems, and promises. Dev Cell 2011;21:193-215.

5. Tang $W$, Zeve $D$, Suh JM, et al. White fat progenitor cells reside in the adipose vasculature. Science 2008;322:583-586.

6. Dellavalle A, Sampaolesi M, Tonlorenzi R, et al. Pericytes of human skeletal muscle are myogenic precursors distinct from satellite cells. Nat Cell Biol 2007:9:255-267.

7. Dore-Duffy P, Katychev A, Wang X, et al. CNS microvascular pericytes exhibit multipotential stem cell activity. J Cereb Blood Flow Metab 2006;26:613-624.

8. Chen WC, Park TS, Murray IR, et al. Cellular kinetics of perivascular MSC precursors. Stem Cells Int 2013;2013:983059.

9. Murray IR, West CC, Hardy WR, et al. Natural history of mesenchymal stem cells, from vessel walls to culture vessels. Cell Mol Life Sci 2013;71:1353-1374.

10. Hildebrandt HA, Gossl M, Mannheim D, et al. Differential distribution of vasa vasorum in different vascular beds in humans. Atherosclerosis 2008;199:47-54.

11. Langheinrich AC, Michniewicz A, Sedding DG, et al. Correlation of vasa vasorum neovascularization and plaque progression in aortas of apolipoprotein $\mathrm{E}(-/-) /$ low-density lipoprotein(-/-) double knockout mice. Arterioscler Thromb Vasc Biol 2006;26:347-352.

12. Doyle B, Caplice N. Plaque neovascularization and antiangiogenic therapy for atherosclerosis. J Am Coll Cardiol 2007;49:2073-2080.

13. Tanaka K, Nagata D, Hirata $Y$, et al. Augmented angiogenesis in adventitia promotes growth of atherosclerotic plaque in apolipoprotein E-deficient mice. Atherosclerosis 2011;215:366-373.

14. Mulligan-Kehoe MJ. The vasa vasorum in diseased and nondiseased arteries. Am J Physiol Heart Circ Physiol 2010;298:H295-H305.

15. Majesky MW, Dong XR, Hoglund V, et al. The adventitia: a dynamic interface containing resident progenitor cells. Arterioscler Thromb Vasc Biol 2011;31:1530-1539.

16. Bautch VL. Stem cells and the vasculature. Nat Med 2011;17:1437-1443.

17. Kawabe J, Hasebe N. Role of the vasa vasorum and vascular resident stem cells in atherosclerosis. Biomed Res Int 2014;2014:701571.

18. Tilki $D$, Hohn HP, Ergun $B$, et al. Emerging biology of vascular wall progenitor cells in health and disease. Trends Mol Med 2009;15:501-509.

19. Tang Z, Wang A, Yuan F, et al. Differentiation of multipotent vascular stem cells contributes to vascular diseases. Nat Commun 2012;3:875.

20. Obinata M. Conditionally immortalized cell lines with differentiated functions established from temperature-sensitive T-antigen transgenic mice. Genes Cells 1997;2:235-244.

21. Kondo T, Hosoya $\mathrm{K}$, Hori $\mathrm{S}$, et al. Establishment of conditionally immortalized rat retinal pericyte cell lines (TR-rPCT) and their application in a co-culture system using retinal capillary endothelial cell line (TR-iBRB2). Cell Struct Funct 2003;28:145-153.

22. Shimizu F, Sano Y, Maeda T, et al. Peripheral nerve pericytes originating from the blood-nerve barrier expresses tight junctional molecules and transporters as barrier-forming cells. J Cell Physiol 2008;217:388-399.

23. Asanome A, Kawabe J, Matsuki $M$, et al. Nerve growth factor stimulates regeneration of perivascular nerve, and induces the maturation of microvessels around the injured artery. Biochem Biophys Res Commun 2014;443:150-155.

24. Kawabe J, Yuhki K, Okada $M$, et al. Prostaglandin 12 promotes recruitment of endothelial progenitor cells and limits vascular remodeling. Arterioscler Thromb Vasc Biol 2010;30:464-470.

25. Yamauchi A, Kawabe J, Kabara $M$, et al. Apurinic/apyrimidinic endonucelase 1 maintains adhesion of endothelial progenitor cells and reduces neointima formation. Am J Physiol Heart Circ Physiol 2013;305:H1158-H1167.

26. Aburakawa $\mathrm{Y}$, Kawabe J, Okada $\mathrm{M}$, et al. Prostacyclin stimulated integrin-dependent angiogenic effects of endothelial progenitor cells and mediated potent circulation recovery in ischemic hind limb model. Circ J 2013;77:1053-1062. 
27. Middleton J, Americh L, Gayon $\mathrm{R}$, et al. A comparative study of endothelial cell markers expressed in chronically inflamed human tissues: MECA-79, Duffy antigen receptor for chemokines, von Willebrand factor, CD31, CD34, CD105 and CD146. J Pathol 2005;206:260-268.

28. Bardin N, Frances V, Lesaule G, et al. Identification of the S-Endo 1 endothelial-associated antigen. Biochem Biophys Res Commun 1996;218:210-216.

29. Wilkinson FL, Liu Y, Rucka AK, et al. Contribution of VCAF-positive cells to neovascularization and calcification in atherosclerotic plaque development. J Pathol 2007;211:362-369.

30. Laitinen L. Griffonia simplicifolia lectins bind specifically to endothelial cells and some epithelial cells in mouse tissues. Histochem J 1987; 19:225-234.

31. Crisan M, Corselli M, Chen WC, et al. Perivascular cells for regenerative medicine. J Cell Mol Med 2012;16:2851-2860.

32. Tintut $Y$, Alfonso $Z$, Saini $T$, et al. Multilineage potential of cells from the artery wall. Circulation 2003;108:2505-2510.

33. Tigges U, Komatsu M, Stallcup WB. Adventitial pericyte progenitor/ mesenchymal stem cells participate in the restenotic response to arterial injury. J Vasc Res 2013;50:134-144.

34. Birbrair A, Zhang T, Wang ZM, et al. Type-1 pericytes participate in fibrous tissue deposition in aged skeletal muscle. Am J Physiol Cel Physiol 2013;305:C1098-C1113.

35. Birbrair A, Zhang T, Wang ZM, et al. Skeletal muscle pericyte subtypes differ in their differentiation potential. Stem Cell Res 2013;10:67-84.

36. Kovacic JC, Boehm M. Resident vascular progenitor cells: an emerging role for non-terminally differentiated vessel-resident cells in vascular biology. Stem Cell Res 2009;2:2-15.

37. Campagnolo P, Cesselli D, Al Haj Zen A, et al. Human adult vena saphena contains perivascular progenitor cells endowed with clonogenic and proangiogenic potential. Circulation 2010;121: 1735-1745.

38. Corselli $M$, Chen CW, Sun B, et al. The tunica adventitia of human arteries and veins as a source of mesenchymal stem cells. Stem Cells Dev 2012;21:1299-1308.

39. Naito $\mathrm{H}$, Kidoya $\mathrm{H}$, Sakimoto $\mathrm{S}$, et al. Identification and characterization of a resident vascular stem/progenitor cell population in preexisting blood vessels. EMBO J 2012;31:842-855.

40. Pasquinelli G, Tazzari PL, Vaselli $\mathrm{C}$, et al. Thoracic aortas from multiorgan donors are suitable for obtaining resident angiogenic mesenchymal stromal cells. Stem Cells 2007;25:1627-1634.

41. Zorzi $P$, Aplin AC, Smith KD, et al. Technical advance: the rat aorta contains resident mononuclear phagocytes with proliferative capacity and proangiogenic properties. J Leukoc Biol 2010;88:1051-1059.

42. Oswald J, Boxberger S, Jorgensen B, et al. Mesenchymal stem cells can be differentiated into endothelial cells in vitro. Stem Cells 2004;22:377-384.

43. Takashima $Y$, Era $T$, Nakao $K$, et al. Neuroepithelial cells supply an initial transient wave of MSC differentiation. Cell 2007;129: 1377-1388.

44. Morikawa S, Mabuchi Y, Niibe K, et al. Development of mesenchymal stem cells partially originate from the neural crest. Biochem Biophys Res Commun 2009:379:1114-1119.

45. Takahashi $Y$, Sipp D, Enomoto $H$. Tissue interactions in neural crest cell development and disease. Science 2013:341:860-863.

46. Chang L, Milton H, Eitzman DT, et al. Paradoxical roles of perivascular adipose tissue in atherosclerosis and hypertension. Circ J 2013;77: 11-18.

47. Shimabukuro M, Kozuka C, Taira S, et al. Ectopic fat deposition and global cardiometabolic risk: new paradigm in cardiovascular medicine. J Med Invest 2013;60:1-14. 